\title{
Molecular-marker-based Genetic Analysis of Tepary Bean-derived Common Bacterial Blight Resistance in Different Developmental Stages of Common Bean
}

\author{
Geunhwa Jung and Paul W. Skroch \\ Department of Horticulture, University of Wisconsin, Madison, WI 53706 \\ Dermot P. Coyne \\ Department of Horticulture, University of Nebraska, Lincoln, NE 68583 \\ James Nienhuis \\ Department of Horticulture, University of Wisconsin, Madison, WI 53706
}

E. Arnaud-Santana

Arroyo Loro Experiment Station, San Juan de la Maguana, Dominican Republic

H.M. Ariyarathne

Department of Horticulture, University of Nebraska, Lincoln, NE 68583

Shawn M. Kaeppler

Department of Agronomy, University of Wisconsin, Madison, WI 53706

Mark J. Bassett

Horticultural Sciences Department, University of Florida, Gainesville, FL 32611

\begin{abstract}
ADDITIONAL INDEX woRDs. Xanthomonas campestris pv. phaseoli, linkage mapping, recombinant inbred lines, Phaseolus vulgaris, Phaseolus acutifolius, partial resistance, randomly amplified polymorphic DNA, RAPD, epistasis, seedcoat color, flower color
\end{abstract}

\begin{abstract}
Randomly amplified polymorphic DNA (RAPD) molecular markers were used to construct a partial genetic linkage map in a recombinant inbred population derived from the common bean (Phaseolus vulgaris $\mathbf{L}$.) cross PC-50 $\mathrm{X}$ $X A N-159$ for studying the genetics of bacterial disease resistance in common bean. The linkage map spanned $426 \mathrm{cM}$ and included 168 RAPD markers and 2 classical markers with 11 unassigned markers. The seventy recombinant inbred lines were evaluated for resistance to two strains of common bacterial blight [Xanthomonas campestris pv. phaseoli (Smith) Dye] $(X c p)$. Common bacterial blight (CBB) resistance was evaluated for $X c p$ strain EK-11 in later-developed trifoliolate leaves and for $X c p$ strains, DR-7 and EK-11, in first trifoliolate leaves, seeds, and pods. One to four quantitative trait loci (QTLs) accounted for $18 \%$ to $53 \%$ of the phenotypic variation for traits. Most significant effects for CBB resistance were associated with one chromosomal region on linkage group 5 and with two regions on linkage group 1, of the partial linkage map. The chromosomal region (a 13-cM interval) in linkage group 5 was significantly associated with resistance to $X c p$ strains DR-7 and EK-11 in leaves, pods, and seeds. The regions in linkage group 1 were also significantly associated with resistance to both $X c p$ strains in more than one plant organ. In addition, a seedcoat pattern gene $(C)$ and a flower color gene $\left(v^{I L e}\right)$ were mapped in linkage groups 1 and 5 , respectively, of the partial linkage map. The $V$ locus was found to be linked to a QTL with a major effect on CBB resistance.
\end{abstract}

Common bacterial blight (CBB), incited by Xanthomonas campestris pv, phaseoli (Smith) Dye $(X c p)$, is one of the most serious seedborne diseases of common bean (Phaseolus vulgaris L.). CBB causes economic losses due to a reduction in seed yield and seed quality in dry-bean-producing regions worldwide (Saettler, 1989). Symptomless seeds internally infected with disease are considered potential primary inoculum sources (Weller and Saettler, 1980). The most effective long-term control strategy for this disease is breeding resistant cultivars (Sanders and Schwartz, 1980).

Received for publication 28 May 1996. Accepted for publication 19 Dec. 1996. Published as Nebraska Agricultural Research Division journal series paper no. 11460 . Research was conducted under projects $20-036$ and 20-042. We acknowledge financial support from the Title XII Bean/Cowpea CRSP (AID contract no. DNA-1310-G-SS-6008-00). We also appreciate assistance of technicians Lisa Sutton and James Reiser. The cost of publishing this paper was defrayed in part by the payment of page charges. Under postal regulations, this paper therefore must be hereby marked advertisement solely to indicate this fact.
Germplasm with CBB resistance has been identified in $P$. vulgaris (Coyne and Schuster, 1983). For CBB resistance, differential leaf and pod resistance, quantitative patterns of inheritance, and low heritability have been reported (Arnaud-Santana et al., 1994; Coyne and Schuster, 1974; Valladares-Sanchez et al., 1979). However, although extensive research on the development of $\mathrm{CBB}$ resistant varieties has been conducted for many years, high levels of resistance have not been reported. Yoshii et al. (1978) found that genetic variation of the pathogen is a potential problem in the search for germplasm tolerant to this bacterium and in breeding for tolerant cultivars. The lack of high levels of $\mathrm{CBB}$ resistance in $P$. vulgaris germplasm has been the impetus for screening Phaseolus species for resistance and for research on interspecific hybridization.

By far, the highest levels of CBB resistance have been reported in tepary bean ( $P$. acutifolius) (Drijfhout and Blok, 1987; Schuster et al., 1983) and in runner bean (P. coccineus) (Mohan, 1982). McElroy (1985) studied CBB resistance in $P$. acutifolius and the XAN lines, XAN-159, XAN-160, and XAN-161. These three lines 
were developed at CIAT (Centro Internacional de Agricultura Tropical) through six generations of pedigree selection of progenies derived from interspecific crosses between $P$. vulgaris and $P$. acutifolius accession PI 319443 reported by Thomas and Waines (1984). McElroy (1985) reported that the CBB resistance in $P$. acutifolius, accession PI 319443, showed quantitative inheritance, predominantly additive gene effects, and partial dominance for CBB resistance. The data were found to be consistent with the hypothesis of one prominent major gene and two other genes of lesser effect controlling resistance. McElroy (1985) concluded that it is likely that most genes controlling CBB resistance in P. acutifolius accession PI 319443, if not all, have been recovered in XAN-159.

The genetics of CBB resistance in common bean have been studied, using molecular marker linkage maps, by Nodari et al. (1993b) and Jung et al. (1996). However, there have been no attempts to characterize the genomic locations of resistance genes derived from the important $P$. acutifolius source PI 319443. The objectives of the research reported here were to 1) identify linkages between molecular genetic markers and quantitative trait loci (QTLs) conferring common bacterial blight resistance in a population of recombinant inbred lines derived from the common bean cross PC-50 $\times$ XAN-159 and 2) characterize linkage relationships among QTLs for resistance in different plant organs and to different pathogen strains.

\section{Materials and Methods}

Mapping Population. A total of $70 \mathrm{~F}_{6} \mathrm{RI}$ (recombinant inbred) lines from the cross PC-50 $\times$ XAN-159 was developed using the single seed descent breeding method (Arnaud-Santana et al., 1994). 'PC-50' [Dominican Republic (DR)] has pink flowers $\left(v^{\text {lae }}\right)$ and red/cartridge buff marbled seedcoats and is susceptible to CBB in leaves, pods, and seeds. It was derived from a single plant selection made by F. Saladin (unpublished data, Ministry of Agriculture, Dominican Republic) in the landrace Pompadour Checa. XAN-159 has purple flowers $(V)$ and black/cartridge buff speckled seedcoats and was developed for leaf resistance to CBB at CIAT (McElroy, 1985) by selection from the interspecific cross [('Pinto UI 114' x PI 319441) X P. acutifolius PI 319443] x 'Masterpiece' made by Thomas and Waines (1984).

Phenotypic Data. Xcp strains EK-11 and DR-7 were used for inoculations (Schuster et al., 1983). Aggour et al. (1989) and ArnaudSantana et al. (1994) referred to strain DR-7 as V4S1. Strain V4S1 was erroneously referred to as DR-12 by Arnaud-Santana (1992). Strain EK-11 was referred to as V3S8 by Aggour et al. (1989), Arnaud-Santana(1992), Arnaud-Santanaetal.(1994), and Ariyarathne (1994). All Xcp strains used here were obtained from A.K. Vidaver, Dept. of Plant Pathology, Univ. of Nebraska, Lincoln.

In 1991, the $70 \mathrm{RI} \mathrm{F}_{6}$ lines and their parents were grown in the greenhouse in Lincoln and inoculated on first trifoliolate leaves, pods, and seeds with $X c p$ strain DR-7 and first trifoliolate leaves with $X c p$ strain EK-11. Inoculation and disease rating were performed as described by Arnaud-Santana et al. (1994). A randomized complete-block design with two replications and three plants per replicate was used. The day/night temperature in the greenhouse for the experiment was maintained at $28^{\circ} \mathrm{C}$ and $25 \pm 3^{\circ} \mathrm{C}$. The natural day length ranged from 12 to $16 \mathrm{~h}$ during the period April to July 1991.

In 1992, the $70 \mathrm{RI} \mathrm{F}_{7}$ lines and their parents were grown in the growth chamber and inoculated on first trifoliolate leaves with Xcp strain DR-7. Inoculation and disease rating were performed as described by Arnaud-Santana et al. (1994). A randomized completeblock design with two replications (three plants per replicate) was used. The day/night temperature in the growth chamber for the experiment was maintained at $28^{\circ} \mathrm{C}$. The day length was set at $16 \mathrm{~h}$.

In 1993 , the $70 \mathrm{RIF}_{8}$ lines developed from the $\mathrm{F}_{6}$ population and their parents were grown in the greenhouse in Lincoln and inoculated on first trifoliolate leaves, later-developed trifoliolate leaves, pods, and seeds with Xcp strain EK-11 (Ariyarathne, 1994). For this experiment disease-screening methods and disease-rating scales were as described by Arnaud-Santana et al. (1994). A randomized complete-block design with two replications (three plants per replicate) was used. The day/night temperature in the greenhouse for the experiment was maintained at $28 \pm 3{ }^{\circ} \mathrm{C}$ and 22 $\pm 2{ }^{\circ} \mathrm{C}$. The natural day length ranged from 10 to $12 \mathrm{~h}$ during October 1993 to January 1994.

In $1995,70 \mathrm{RI} \mathrm{F}_{8}$ lines from the cross PC-50 x XAN-159 were classified for seedcoat pattern, seedcoat color, and flower color and genotyped at the $C$ and $V$ loci (Prakken, 1970, 1972). Genotypic differences at the $V$ locus determine the flower color difference between the purple $(V)$ flowered $X A N-159$ and pink $\left(v^{\text {lae }}\right)$ flowered PC-50. At the $C$ locus, PC-50 carries the $C^{m a}$ allele for marbled seedcoat pattern, which is distinguishable from the rhomboidal striping pattern conferred by the $C^{\text {rho }}$ allele carried by XAN159. The dominant $R$ allele for red seedcoat color at the complex $C$ locus accompanies the marbled seedcoat pattern in PC-50 and no recombinants were found among the 70 recombinant inbred lines used in this study.

The phenotypic data were checked for deviations from normality for CBB ratings of leaves, seeds, and pods using a W statistic (Shapiro and Wilk, 1965).

Molecular Marker data. Total genomic DNA was prepared from lyophilized fully expanded trifoliolate leaves of the above 70 $\mathrm{F}_{6} \mathrm{RI}$ lines and the two parental lines using the method previously described by Skroch and Nienhuis (1995). The polymerase chain reaction was used to generate randomly amplified polymorphic DNA (RAPD) (Williams et al., 1990) genetic markers in an air thermalcycler (model 1605; Idaho Technology) in thin-walled glass capillary tubes as described by Skroch and Nienhuis (1995).

The 10-base primers used for the RAPD reactions were obtained from Operon Technologies (Alameda, Calif.) and the Univ. of British Columbia, Vancouver. A total of about 1000 RAPD primers were initially tested to detect polymorphisms between parental lines PC50 and XAN-159. Seventy-seven primers were selected from this set for marker analysis of the population. Each segregating marker was named using its approximate size, in base pairs, combined with the primer name as described by Jung et al. (1996).

LINKAGE MAP CONSTRUCTION. RAPD markers, the $C$ gene for the seedcoat pattern (reddish mottled verses rhomboidal striping), and the $V$ gene for flower color (purple verses pink), were mapped using MAPMAKER Macintosh version 2.0 software (Lander et al., 1987). The logarithm of odds (LOD) score of 3.0 was used as a linkage threshold with 0.3 as the maximum recombination fraction for linkage groups. Map distances (cM) were estimated using recombination fractions and Kosambi's mapping function (Kosambi, 1944) for ordered marker loci. Segregation at each marker locus was checked for deviation from the expected 1:1 ratio in $\mathrm{F}_{6} \mathrm{RI}$ lines based on a chi-square goodness of fit test (Table 1). Subsequent to the initial map construction, 120 additional markers were evaluated in this population but genome coverage was not improved significantly so these additional markers were not used for QTL detection.

QTL IDENTIFICATION. The QTL analysis of $X c p$ strain DR-7 in first trifoliolate leaves was based on means for 2 years' data (1991 and 1992). For the QTL analysis of Xcp strain EK-11 in first trifoliolate leaves the analysis was also based on means for 2 years' 
Table 1. Description of genetic linkage map based on 168 randomly amplified polymorphic DNA markers and seedcoat color $(C$ locus) and flower color ( $V$ locus) markers, segregating among recombinant inbred lines derived from the common bean cross PC-50 x XAN-159.

\begin{tabular}{lcccc}
\hline \hline Linkage group & Number & Map distance $^{z}$ & Marker density $^{y}$ & Distorted segregation $^{\mathrm{x}}$ \\
\hline 1 & 37 & 120 & 3.2 & 0 \\
2 & 24 & 43 & 1.8 & 2 \\
3 & 6 & 51 & 8.5 & 0 \\
4 & 11 & 51 & 4.6 & 0 \\
5 & 23 & 13 & 0.6 & 19 \\
6 & 20 & 37 & 1.9 & 2 \\
7 & 30 & 33 & 1.1 & 19 \\
8 & 8 & 18 & 2.3 & 8 \\
9 & 7 & 36 & 5.1 & 1 \\
10 & 4 & 24 & 6.0 & 1 \\
Unassigned markers & 11 & & & 3 \\
Total & 181 & 426 & 2.4 & 55 \\
zap distance & & & \\
\hline
\end{tabular}

${ }^{2}$ Map distance (cM) based on the Kosambi's mapping function.

'Map length (cM) divided by the number of markers.

${ }^{\mathrm{x}}$ Number of markers deviating significantly from the expected $1: 1$ segregation $(P<0.05)$.

data (1991 and 1993). However, detection of marker locus-QTL linkages for resistance to both $X c p$ strains in later-developed trifoliolate leaves, seeds, and pods was based on 1 year's data. For QTL detection, the data were analyzed based on single-factor analysis of variance (ANOVA) for each pairwise combination of quantitative traits and marker loci. F tests $(P<0.05)$ were used to determine if significant differences in trait expression were associated with differences in marker-locus genotypic classes (Edwards et al., 1987). Significant markers in the same linkage group were considered as one QTL if the distance between them did not exceed $50 \mathrm{cM}$ (Paterson et al., 1991). When significant markers were linked $(\leq 50 \mathrm{cM})$, the marker locus having the greatest $R^{2}$ value was assumed to be the most likely position of the QTL and used in all further analysis. Marker loci significantly associated with trait variation by single-factor ANOVA were then entered into a stepwise multiple regression analysis to select the best set of markers and compute the total phenotypic variation explained by marker loci. A relatively high $P$ value $(P=0.05)$ was used for detecting individual QTLs and for stepwise regression analysis with the understanding that this may have increased the experimental Type I error rate. However, lower stringency of detection is recommended as a way to reduce the probability of committing Type II errors (Edwards et al., 1992). In addition, we report all marker locus-QTL associations objectively in terms of their statistical significance ( $P$ value). The method of interval mapping (Lander and Botstein, 1989) was also used for localizing QTLs and estimating their genetic effects. The LOD score for the QTL threshold was set at 2.0 based on theoretical considerations (Lander and Botstein, 1989). Only linkages of three or more markers were included in the interval mapping analysis.

Molecular marker loci that were significant at the $5 \%$ probability level in a final model by the stepwise multiple regression analysis were tested for significant interactions by two-way ANOVA. Significant interactions were then included in the stepwise regression analysis to determine whether accounting for these interactions would improve the phenotypic variation for CBB resistance explained by markers significantly associated with trait variation (Freyre et al., 1994). In addition, marker loci showing significant interactions were further analyzed on a pairwise basis. Differences between means of the four possible two locus marker genotypes were tested for significance using contrasts involving least square means. Differences among the means of four genotypes and levels of significance were used to consider epistatic models.

\section{Results and Discussion}

RAPD MARKER SEGREGATION. Based on an initial screen of about 1000 RAPD primers, 410 primers were found that amplified at least one RAPD fragment, polymorphic between the parents. These 410 primers amplified a total of 520 polymorphic RAPD markers. Thus, on average, about one polymorphic RAPD marker was found for every two primers tested and polymorphic primers amplified an average of 1.3 polymorphic fragments per primer. Seventy-seven primers were selected from this set based on the number and quality of amplified polymorphic fragments. For these 77 primers, 179 markers were amplified and scored for the 70 recombinant inbred lines derived from the cross PC-50 $\times$ XAN159. The RAPD map reported by Jung et al. (1996) was not used in the present study because the proportion of markers segregating in the BAC $6 \times$ HT 7719 population used in this previous study and the PC-50 $\times$ XAN-159 population used here was extremely low.

Of the 179 RAPD markers scored, $124(69 \%)$ fit the expected 1:1 ratio based on a chi-square goodness of fit test (Table 1). Skewed segregations $(P<0.05)$ were detected for 55 of the 179 RAPD markers, comprising 11 distinct regions distributed over 7 linkage groups, with 33 favoring the PC-50 allele and 22 favoring the XAN-159 allele (Table 1). Lower proportions ( $8 \%$ and $9 \%$ ) of RFLP markers with segregation distortion have been observed in common bean $\mathrm{F}_{2}$ populations (Nodari et al., 1993a; Vallejos et al., 1992). However, Jung et al. (1996) also reported a relatively high proportion (24\%) of RAPD markers showing segregation distortion in an $F_{6}$ RI population. The cause of the high percentage of segregation distortion for RAPD markers in these RI mapping populations is unknown. However, several factors could have contributed to this result, including genetic drift and natural selection, which may have occurred during inbreeding.

LINKAGE MAP CONSTRUCTION. One hundred eighty-one markers were grouped into ten linkage groups with eleven unassigned markers (Table 1). A number of markers either mapped to identical positions as other markers or were clustered within very short linkage distances from other markers. From 1 to 17 loci per linkage group had more than one RAPD marker mapped to it. Thus, only 68 RAPD markers and the flower color and seedcoat pattern markers are shown in the linkage map (Fig. 1). Although 10 linkage groups were described, the haploid chromosome number of $P$. vulgaris is $11(2 \mathrm{n}=22)$; thus, at least one more linkage group remains to be detected. The number of markers per linkage group 

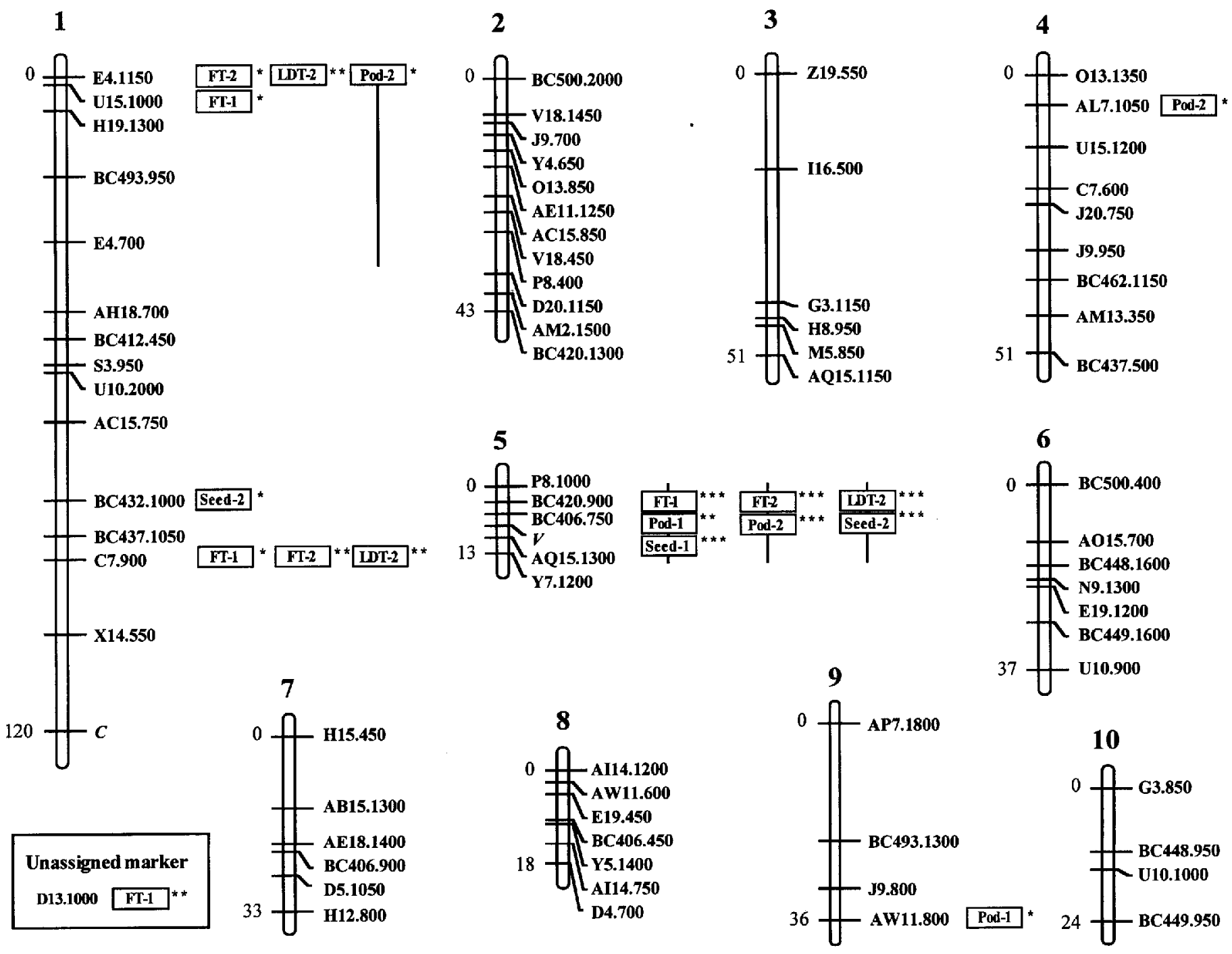

Fig. 1. Randomly amplified polymorphic DNA (RAPD) marker linkage map. For marker locus -trait associations significant in the multiple regression analysis, the most probable locations of detected quantitative trait loci (QTLs) are indicated for 1) resistance to common bacterial blight strain DR-7 in first trifoliolate leaves (FT-1), pods (Pod-1), and seeds (Seed-1) and 2) resistance to common bacterial blight strain EK-11 in first trifoliolate leaves (FT-2), later-developed trifoliolate leaves (LDT-2), pods (Pod-2), and seeds (Seed-2). The significance of each marker locus-QTL association in the stepwise regression analysis is indicated (***;*** significant at $P<0.05$, 0.01 , or 0.001 ). The gene and marker names are given on the right and map distances are given (cM) on the left of each linkage group. For each QTL detected by interval mapping with a logarithm of odds (LOD) greater than 2,0, lines emanating from boxes indicate two LOD confidence intervals.

ranged from 4 to 37 (Table 1). Three intervals located in linkage groups 1,3 , and 9 were larger than $20 \mathrm{cM}(20.8,24.1$, and $20.9 \mathrm{cM}$, respectively), with the LOD score for linkage of flanking markers above the threshold of 3.0 (Fig. 1). Most intervals (>90\%) were smaller than $10 \mathrm{cM}$.

The linkage map reported here spans $426 \mathrm{cM}$, which is similar in length to the map reported by Jung et al. (1996), also based on a relatively narrow cross and much shorter than the $871-\mathrm{cM}$ (Nodari et al., 1993a) and 963-cM (Vallejos et al., 1992) maps constructed using RFLP markers and relatively wide crosses within $P$. vulgaris (inter-genepool crosses). Moreover, in addition to the 179 RAPD markers evaluated for this study, more than 100 (120) additional RAPD markers have been mapped in the PC-50x $\mathrm{XAN}-159$ population without increasing the genome coverage significantly (unpublished data). Compared to the results obtained using restriction fragment-length polymorphisms (RFLPs), reduced genome coverage was observed for the RAPD map constructed here as well as the map reported by Jung et al. (1996). RFLP maps reported by Nodari et al. (1993a) and Vallejos et al. (1992) were based on 143 and 244 RFLP loci, respectively. Thus, the better genome coverage achieved in these RFLP mapping studies was not due to more markers. One possible explanation for the results observed with RAPD markers may be a nonrandom distribution of RAPD marker loci in the common bean genetic map. In addition, the distribution of RAPD markers in the partial linkage map constructed here might have been effected by introgression of small regions of the $P$. acutifolius genome during the development of XAN-159. Such introgressed regions would be expected to be highly polymorphic for RAPD markers. If the failure to achieve better genome coverage is due to an uneven distribution of marker polymorphism, then map expansion might be possible if enough markers are evaluated. Alternatively, large regions of the parental genomes might be very similar or even identical by descent. Expansion of the map into these regions may be impossible in this cross.

The PC-50 x XAN- 159 population was originally developed in the context of a dry-bean-breeding program and was designed to achieve breeding objectives rather than the objectives of genomic research. The parents were not chosen to maximize the level of marker polymorphism, which made detecting marker polymor- 


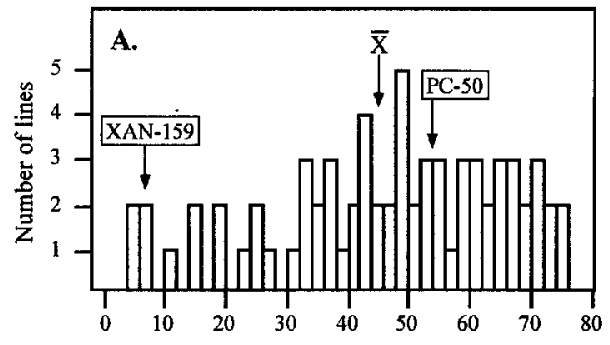

Disease rating
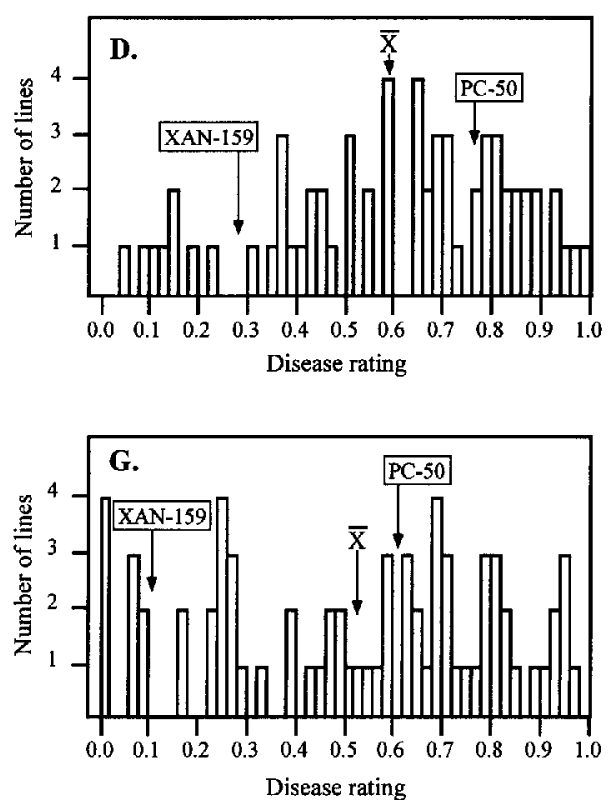
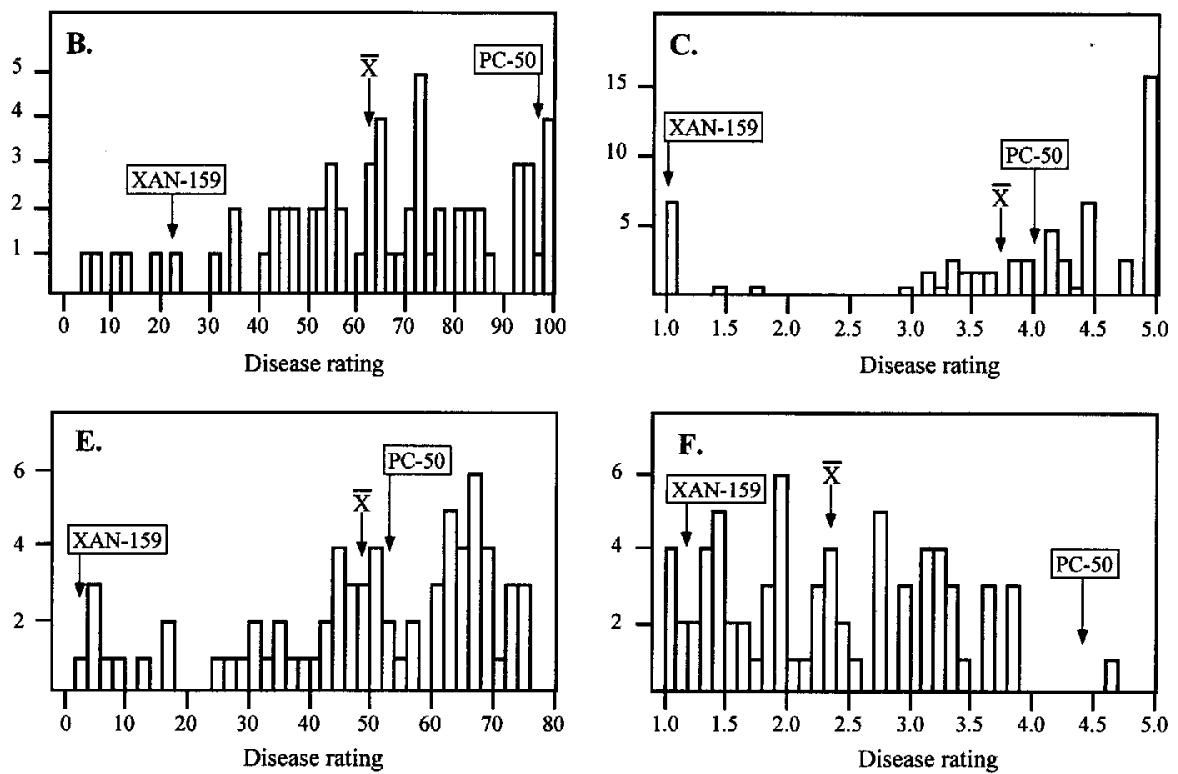

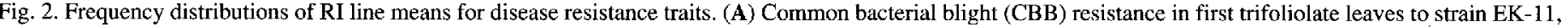

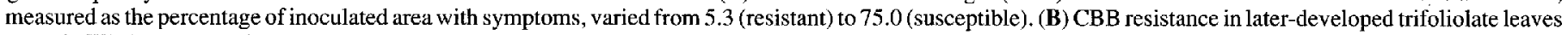

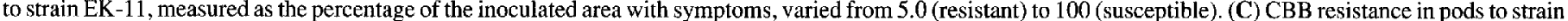

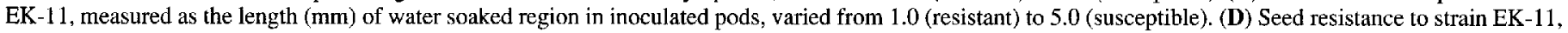

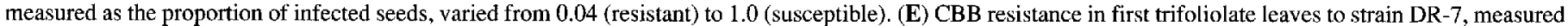

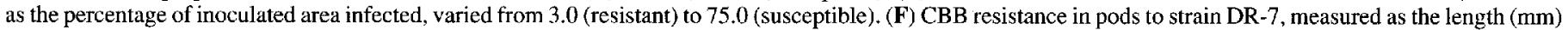

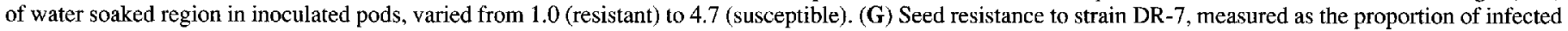
seeds, varied from 0.00 (resistant) to 0.97 (susceptible).

phisms more difficult and perhaps reduced the genome coverage of the resulting linkage map. The results of this study may be interpreted to indicate that researchers intending to do genome analysis should use wider crosses. In fact, the populations used for constructing RFLP maps in common bean (described above) were developed from wide crosses with the objective of genome analysis. However, ultimately, for molecular markers to be useful in breeding programs, linkage maps are needed that contain markers that are informative in typical breeding populations. Thus, while the failure to achieve complete genome coverage can be seen as undesirable, applying molecular markers to practical plant breeding problems necessitates mapping studies in such populations.

LOCATION OF CLASSICAL MARKERS. Two classical marker loci, $C$ and $V$, were mapped in linkage groups 1 and 5, respectively (Fig. 1). The genotype at the $C$ locus was determined by the pattern difference between the reddish marbled seedcoat of PC-50 and the speckled rhomboidal striping with fine dotting of the XAN-159 seedcoat. The $C$ locus was mapped about $10 \mathrm{cM}$ from marker $\mathrm{X} 14.550$ at the end of linkage group 1 . The $V$ locus, determining the flower color difference between the purple-flowered $(V)$ XAN159 and pink-flowered ( $\left.v^{\text {lae }}\right)$ PC-50, was mapped to a location in linkage group 5 flanked on one side $3.2 \mathrm{cM}$ from marker $\mathrm{BC} 406.750$ and on the other side $2.5 \mathrm{cM}$ from marker AQ15.1300 (Fig. 1). Our results are consistent with previously observed results showing no linkage between the $C$ and $V$ loci in a classical linkage map (Bassett, 1991).

Disease REsistance TRAIT DISTRIBUTIONS. The quantitative inheritance of $\mathrm{CBB}$ resistance in leaves, pods, and seeds for the RI lines derived from the cross of PC-50 and XAN-159 agrees with previous reports (Aggour et al., 1989; Valladares-Sanchez et al., 1979; Webster et al., 1983). All trait distributions (Fig. 2) deviated significantly from normal $(P<0.05)$. Transformations to improve the normality of the data were unsuccessful and untransformed data was used for QTL analysis. Although a normal distribution of values is preferred for QTL analysis, QTL detection has often been performed for traits with skewed distributions (Doebley et al., 1990; Nienhuis et al., 1987; Paterson et al., 1991). Putative transgressive segregation was observed for susceptibility to both CBB strains. For strain EK-11, higher susceptibility than PC-50 was recorded for $28,4,35$, and 21 lines for $C B B$ resistance in first trifoliolate leaves, later-developed trifoliolate leaves, pods, and seeds, respectively. For strain DR-7, susceptibility higher than PC50 was recorded for 32,1 , and 33 RI lines for first trifoliolate leaves, pods, and seeds, respectively. For traits having large numbers of lines with mean disease ratings greater than PC-50, distributions were clearly skewed toward susceptibility (Fig. 2). Transgressive segregation for resistance was less evident. XAN159 is highly resistant to both bacterial strains and its disease rating 
is near the bottom of the rating scales for all traits making detection of transgressive segregation for resistance difficult.

QTL aNALYSIS OF CBB RESISTANCE TRAITs. For each diseaseresistance trait measured, one to five significant $(P<0.05)$ marker locus-trait associations were found by single-factor ANOVA (Tables 2 and 3). Eighteen of these were retained in the multilocus models, explaining $18 \%$ to $53 \%$ of the phenotypic variation for the seven traits measured. Three regions, one in linkage group 5 and two in linkage group 1, accounted for 15 of these 18 significant associations (Tables 2 and 3, Fig. 1). Putative QTLs were found on linkage group 5 for CBB resistance in all plant organs and to both bacterial strains (Fig. 1). Variation at marker loci in linkage group 5 accounted for 11 (pod resistance to $X c p$ strain DR-7) to $40 \%$ (resistance in first trifoliolate leaves to strain EK-11) of the phenotypic variation for the CBB resistance traits measured (Tables 2 and 3 ).

The $V$ locus also mapped to linkage group 5 (Fig. 1). In fact, for some traits measured, the $V$ locus itself was the most likely position of the putative QTL (Tables 2 and 3, Fig. 1). Thus, the $V$ locus may be tightly linked to genes for CBB resistance. A visual marker linked to an important gene for CBB resistance would be valuable. However, the allele at this locus conferring purple flower color (associated with resistance) also results in a black seedcoat. Seedcoat colors are one of the criteria on which common-bean market classes are based. Thus, if it is desired to transfer this source of resistance from XAN-159 into a susceptible type with a different seedcoat color, the linkage with the purple flower color allele might have to be broken and it could, therefore, not be used as a marker for $\mathrm{CBB}$ resistance.

On linkage group 1, the two important RAPD marker loci, $\mathrm{C} 7.900$ and $\mathrm{E} 4.1150$, were separated by more than $50 \mathrm{cM}$ (Fig. 1). The large linkage distance between these two loci suggests that at least two QTLs for CBB resistance are located in linkage group 1.
In addition, marker BC432.1000, located about $10 \mathrm{cM}$ from C7.900, was significantly associated with $\mathrm{CBB}$ resistance. The resistant allele is contributed by the susceptible parent for BC432.1000 and C7.900. This fact and the close linkage of BC432.1000 and C7.900 suggests a single QTL for CBB resistance in this region.

The three regions harboring significant marker locus-trait associations for first and later-developed trifoliolate leaves accounted for $42 \%, 51 \%$, and $53 \%$ of the variation for CBB resistance to strain DR-7 in first trifoliolate leaves and strain EK-11 in first and later-developed trifoliolate leaves, respectively (Tables 2 and 3 ). High phenotypic correlations $(0.75,0.57$, and 0.72$)$ between resistance in first trifoliolate leaves to $X c p$ strains DR-7 and EK11 , between first trifoliolate leaves to $X c p$ strain DR-7 and laterdeveloped trifoliolate leaves to $X c p$ strain EK-11, and between first and later-developed trifoliolate leaves to $X c p$ strain EK-11, respectively, are consistent with this result (Table 4 ). Although we cannot determine whether the detection of significant marker locus-QTL associations for the same or closely linked markers was due to pleiotropy or linkage, the results suggest the possibility of single genes with pleiotropic effects at two loci in linkage group 1 and one locus in linkage group 5 that could account for most of the significant marker-locus trait associations found in this study.

Formarker loci C7.900, AL7.1050,BC432.1000, and AI10.1250 significantly associated with resistance to strain EK-11 by singlefactor ANOVA (Table 3), the resistant allele was contributed by the susceptible parent, PC-50. However most of these had small $R^{2}$ values and only marker $C 7.900$ was consistently included in the multilocus models following multiple regression analysis. Marker C7.900 was also found to be significantly associated with resistance to $X c p$ strain DR-7 in first trifoliolate leaves. The consistency of the association of the PC-50 allele at the $\mathrm{C} 7.900$ locus with

Table 2. Summary of the single-factor analysis of variance (ANOVA), interval mapping, and multiple regression analyses of molecular marker and phenotypic data for detecting quantitative trait loci (QTLs) associated with resistance to common bacterial blight (CBB) in different plant organs and for Xanthomonas campestris pv, phaseoli (Xcp) strain DR-7 in recombinant inbred progeny derived from the common bean cross, PC-50 $\mathrm{x}$ XAN-159.

\begin{tabular}{|c|c|c|c|c|c|c|c|}
\hline \multirow{2}{*}{$\begin{array}{l}\text { Plant } \\
\text { organ }\end{array}$} & \multirow[b]{2}{*}{ Location $^{z}$} & \multicolumn{2}{|c|}{ Single-factor ANOVA } & \multirow{2}{*}{$\frac{\text { Interval mapping }}{\text { LOD }^{w}}$} & \multicolumn{2}{|c|}{ Multiple regression } & \multirow{2}{*}{$\begin{array}{l}\text { Linkage } \\
\text { group }^{1} \\
\end{array}$} \\
\hline & & $P>\mathrm{F}^{y}$ & $R^{2 \mathrm{x}}$ & & $P>\mathrm{F}^{v}$ & $R^{2 u}$ & \\
\hline & & \multicolumn{6}{|c|}{$F_{6}$ and $F_{7} R I$ lines inoculated with $X c p$ strain DR-7 (1991 and 1992) } \\
\hline \multirow[t]{6}{*}{ First trifoliolate } & $\mathrm{BC} 420.900(+0)-\mathrm{BC} 406.750$ & 0.0000 & 28 & 3.5 & 0.0000 & 28 & 5 \\
\hline & D13.1000 & 0.0054 & 11 & & 0.0434 & 5 & UM \\
\hline & $\mathrm{U} 15.1000$ & 0.0400 & 6 & 1.0 & 0.0340 & 5 & 1 \\
\hline & $\mathrm{C} 7.900$ & 0.0197 & 8 & 1.0 & 0.0334 & 4 & 1 \\
\hline & Cumulative $R^{2}$ & & & & & 42 & \\
\hline & & \multicolumn{6}{|c|}{$\mathrm{F}_{6} \mathrm{RI}$ lines inoculated with $X c p$ strain DR-7 (1991) } \\
\hline \multirow[t]{4}{*}{ Pod } & BC406.750 & 0.0057 & 11 & 1.7 & 0.0052 & 11 & 5 \\
\hline & AW11.800 & 0.0175 & 8 & 0.7 & 0.0056 & 10 & 9 \\
\hline & $\mathrm{E} 4.700$ & 0.0426 & 6 & & --- & --- & 1 \\
\hline & Cumulative $R^{2}$ & & & & & 21 & \\
\hline \multirow[t]{2}{*}{ Seed } & AQ15.1300 (+0)- $V$ & 0.0002 & 18 & 3.0 & 0.0002 & 18 & 5 \\
\hline & Cumulative $R^{2}$ & & & & & 18 & \\
\hline
\end{tabular}

${ }^{\mathrm{z}}$ Marker or interval significantly associated with trait variation.

${ }^{\mathrm{y}}$ Significance determined for $\mathrm{F}$ tests based on single-factor ANOVA.

xPercentage of phenotypic variation explained by the marker locus based on single-factor ANOVA.

${ }^{\text {w }} \mathrm{OOD}=$ logarithm of odds; value at most likely QTL location as determined by Mapmaker QTL.

${ }^{v}$ Significance levels determined for $F$ tests based on stepwise regression analysis of marker locus-trait associations for markers found to be significant by single-factor ANOVA $(P<0.05)$.

uPercentage of phenotypic variation explained, for significant $(P<0.05)$ marker locus-trait associations, based on stepwise regression analysis. 'Linkage group membership of markers and intervals significantly associated with trait variation for linkage groups as defined in Fig. 1 (UM = unassigned marker). 
resistance across plant organs and bacterial strains strengthens evidence for a QTL effecting CBB resistance linked to this locus. Two other marker loci, D 13.1000 and AW 1 1.800, for which the resistant allele was contributed by the susceptible parent, were significant for $\mathrm{CBB}$ resistance to strain DR-7 by single-factor ANOVA (Table 2). Both were significant in the multiple regression analysis. Although most of these markers were associated with small effects, overall the results strongly indicate the existence of genes contributing to $\mathrm{CBB}$ resistance from the susceptible parent. If PC-50 is carrying CBB resistance genes not in XAN-159, transgressive segregation for CBB resistance would be expected. In fact, many lines were observed having greater susceptibility to both $X c p$ strains (discussed above). Transgressive segregation for resistance to $\mathrm{CBB}$ has previously been reported in common bean (Valladares-Sanchez et al., 1979).

The existence of plant organ-specific CBB resistance genes controlling resistance in leaves and pods has been suggested based on differential leaf and pod reactions to CBB isolates (ValladaresSanchez et al., 1979). The possibility of a genotype $\times$ strain interaction is also supported by the results of Aggour et al. (1989), which indicated significant cultivar and strain interactions for resistance in pods but nonsignificant interactions in leaves using $X c p$ strains DR-7, EK-11, and DRS101. In this study, correlations between leaf resistance and resistance in pods and seeds for $X c p$ strain DR-7 were lower than the correlations of leaf resistance to strain DR-7 with resistance to all four plant organs measured for strain EK-11 (Table 4). These observations suggest a significant strain $\times$ plant organ effect and the possibility of plant organspecific genes for resistance in pods and seeds to $X c p$ strain DR-7.

The results of our QTL analysis indicated similar numbers and effects of QTLs for leaf resistance to both $X c p$ strains. However, some evidence for strain- and organ-specific effects is provided by the association of marker locus D13.1000 with resistance to DR7 in first trifoliolate leaves only. In addition, the significant association of marker AW11.800 with resistance in pods to strain DR-7, accounting for $10 \%$ of the phenotypic variation, was bacterial strain and plant organ specific. However, despite low phenotypic correlations between seed resistance and resistance in other plant organs and to other bacterial strains, no evidence for bacterial-strain- or plant-organ-specific genes was found for seed resistance to strain DR-7. The CBB strain DR-7 is an isolate from the Dominican Republic while EK-11 is an isolate from Nebraska (Schuster et al., 1983). The apparent lack of strain specificity for most of the detected QTL is an important result and indicates linkage of markers to genes for partial resistance to a broad range of CBB strains.

Table 3. Summary of single-factor analysis of variance (ANOVA), interval mapping, and multiple regression analyses of molecular marker and phenotypic data for detecting quantitative trait loci (QTLs) associated with resistance to common bacterial blight (CBB) in different plant organs and for Xanthomonas campestris pv, phaseoli (Xcp) strain EK-11 in recombinant inbred progeny derived from the common bean cross, PC-50 $\mathrm{x}$ $\mathrm{XAN}-159$.

\begin{tabular}{|c|c|c|c|c|c|c|c|}
\hline \multirow{2}{*}{$\begin{array}{l}\text { Plant } \\
\text { organ }\end{array}$} & \multirow[b]{2}{*}{ Location $^{2}$} & \multicolumn{2}{|c|}{ Single-factor ANOVA } & \multirow{2}{*}{$\frac{\text { Interval mapping }}{\text { LOD }^{w}}$} & \multicolumn{2}{|c|}{ Multiple regression } & \multirow{2}{*}{$\begin{array}{r}\text { Linkage } \\
\text { group }^{t} \\
\end{array}$} \\
\hline & & $P>\mathrm{F}^{\mathrm{y}}$ & $R^{2 \mathrm{x}}$ & & $P>\mathrm{F}^{\vee}$ & $R^{2 \mathbf{u}}$ & \\
\hline & & \multicolumn{6}{|c|}{$F_{6}$ and $F_{8}$ RI lines inoculated with $X c p$ strain EK-11 (1991 and 1993) } \\
\hline \multirow[t]{6}{*}{ First trifoliolate } & $\mathrm{BC} 420.900(+0)-\mathrm{BC} 406.750$ & 0.0000 & 40 & 5.4 & 0.0000 & 40 & 5 \\
\hline & $\mathrm{C} 7.900$ & 0.0036 & 12 & 1.7 & 0.0185 & 6 & 1 \\
\hline & $\mathrm{E} 4.1150$ & 0.0240 & 7 & 1.6 & 0.0148 & 5 & 1 \\
\hline & AM2.1500 & 0.0160 & 8 & & $\cdots$ & --- & 2 \\
\hline & Cumulative $R^{2}$ & & & & & 51 & \\
\hline & & \multicolumn{6}{|c|}{$F_{8}$ RI lines inoculated with $X c p$ strain EK-11 (1993) } \\
\hline \multirow[t]{6}{*}{ Later-developed trifoliolate } & $\mathrm{BC} 420.900(+0)-\mathrm{BC} 406.750$ & 0.0000 & 37 & 5.4 & 0.0000 & 37 & 5 \\
\hline & $\mathrm{E} 4.1150$ & 0.0046 & 12 & 1.8 & 0.0025 & 9 & 1 \\
\hline & $\mathrm{C} 7.900$ & 0.0039 & 13 & 1.9 & 0.0060 & 7 & 1 \\
\hline & AL7.1050 & 0.0199 & 9 & & --- & --- & 4 \\
\hline & V18.450 & 0.0084 & 11 & & --- & --- & 2 \\
\hline & Cumulative $R^{2}$ & & & & & 53 & \\
\hline \multirow[t]{5}{*}{ Pod } & $V(+0)-\mathrm{AQ} 15.1300$ & 0.0000 & 30 & 4.6 & 0.0000 & 29 & 5 \\
\hline & $\mathrm{E} 4.1150(+0)-\mathrm{U} 15.1000$ & 0.0010 & 16 & 2.4 & 0.0010 & 12 & 1 \\
\hline & AL7.1050 & 0.0157 & 9 & 1.4 & 0.0263 & 6 & 4 \\
\hline & $\mathrm{E} 4.700$ & 0.0185 & 9 & & --- & -- & 1 \\
\hline & Cumulative $R^{2}$ & & & & & 47 & \\
\hline \multirow[t]{5}{*}{ Seed } & $V(+0)-A Q 15.1300$ & 0.0009 & 18 & 2.4 & 0.0009 & 17 & 5 \\
\hline & BC432.1000 & 0.0315 & 7 & 1.6 & 0.0225 & 8 & 1 \\
\hline & AL7.1050 & 0.0098 & 10 & & --- & --- & 4 \\
\hline & AI10.1250 & 0.0428 & 7 & & --- & --- & UM \\
\hline & Cumulative $R^{2}$ & & & & & 25 & \\
\hline
\end{tabular}

\footnotetext{
${ }^{\mathrm{x}}$ Marker or interval significantly associated with trait variation.
}

'Significance levels determined for F tests based on single-factor ANOVA.

xPercentage of phenotypic variation explained by the marker locus based on single-factor ANOVA.

${ }^{\text {w}} \mathrm{LOD}=$ logarithm of odds; value at most likely QTL location as determined by Mapmaker QTL.

"Significance levels determined for $\mathrm{F}$ tests based on multiple stepwise regression analysis of marker locus-trait associations for markers found to be significant by single-factor ANOVA $(P<0.05)$.

uercentage of phenotypic variation explained, for significant $(P<0.05)$ marker locus-trait associations, based on stepwise regression analysis. tLinkage group membership of markers and intervals significantly associated with trait variation for linkage groups as defined in Fig. 1 (UM $=$ unassigned marker). 
Table 4. Phenotypic correlations for resistance to Xanthomonas campestris pv. phaseoli (Xcp) strains DR-7 and EK-11 in different plant organs for 70 recombinant inbred lines derived form the cross PC-50 x XAN-159.

\begin{tabular}{|c|c|c|c|c|c|c|c|}
\hline \multirow[b]{3}{*}{ Trait } & \multicolumn{7}{|c|}{$X c p$ strain } \\
\hline & \multicolumn{3}{|c|}{ DR-7 } & \multicolumn{4}{|c|}{ EK-11 } \\
\hline & FT & $\mathrm{PD}$ & SD & FT & LDT & $\mathrm{PD}$ & SD \\
\hline \multicolumn{8}{|l|}{$\overline{X c p}$ strain DR-7 (1991) } \\
\hline First trifoliolate (FT) & & 0.17 & $0.40^{* *}$ & $0.75^{* *}$ & $0.57^{* *}$ & $0.67^{* *}$ & $0.47^{* *}$ \\
\hline Pod (PD) & & & $0.28^{*}$ & 0.21 & 0.07 & 0.17 & 0.01 \\
\hline Seed (SD) & & & & $0.32^{* k}$ & $0.29^{*}$ & $0.53^{* *}$ & 0.17 \\
\hline \multicolumn{8}{|l|}{$X c p$ strain EK-11 (1993) } \\
\hline First trifoliolate (FT) & & & & & $0.72^{* *}$ & $0.61^{* *}$ & $0.42^{* *}$ \\
\hline Later-developed trifoliolate (LDT) & & & & & & $0.55^{\star *}$ & $0.49^{* *}$ \\
\hline $\operatorname{Pod}(\mathbf{P D})$ & & & & & & & $0.55^{* *}$ \\
\hline Seed (SD) & & & & & & & \\
\hline
\end{tabular}

McElroy (1985) described quantitative inheritance and additive gene effects for CBB resistance in $P$. acutifolius line PI 319443, from which XAN-159 was derived. McElroy (1985) suggested that one major gene might be involved with its effect modified by the action of two other genes with much lesser effect. Eskridge and Coyne (1996) recently estimated the number of genes for resistance in XAN-159 based on the number of resistant progeny found in an inbred backcross population derived from the cross of PC-50 with XAN-159. Based on this analysis, the estimated number of genes was 5.2,1.1, and 3.3 for leaf, pod, and seed resistance, respectively. The analysis of Eskridge and Coyne (1996), indicating that a small number of genes are responsible for resistance in XAN-159, is consistent with the hypothesis that one major gene in addition to a small number of minor genes of lesser effect is responsible for CBB resistance in XAN-159.

The significant associations of marker loci in linkage group 5 with CBB resistance traits support the hypothesis of one gene with a major effect. The results also strongly support the existence of a gene for CBB resistance in linkage group 1 associated with marker locus E4.1150 with a smaller effect. Only two other candidate marker-QTL linkages were detected for CBB resistance derived from XAN-159. These included markers AM2.1500 and V18.450, but neither of these were significant for more than one trait and they were not included in the final multilocus models. Incomplete genome coverage may have resulted in failure to detect some loci with significant effects. However, alternative approaches for discovering undetected QTLs may be necessary since efforts to expand the linkage map were largely unsuccessful.

INTERACTIONS AMONG DETECTED QTLS. Two-way ANOVA was conducted for pairwise combinations of markers significantly associated with $\mathrm{CBB}$ resistance traits by stepwise regression analysis. Seventeen possible pairwise combinations of markers were possible within traits. Significant interactions between markers $\mathrm{E} 4.1150$ and $\mathrm{BC} 420.900$ in linkage groups 1 and 5 were detected for resistance to $X_{c p}$ strain EK-11 in first and laterdeveloped trifoliolate leaves $(P=0.0030$ and 0.0002 , respec-

Table 5. Effects of interacting quantitative trait loci (QTLs) on mean of resistance to common bacterial blight (CBB) and mean comparisons among four genotypes involving the pairs of allele at given loci.

\begin{tabular}{|c|c|c|c|}
\hline \multirow[b]{2}{*}{ Locus/trait } & \multicolumn{2}{|c|}{ Mean CBB resistance ${ }^{2}$} & \multirow[b]{2}{*}{ Difference $^{y}$} \\
\hline & XAN-159/XAN-159 & $\mathrm{PC}-50 / \mathrm{PC}-50$ & \\
\hline & \multicolumn{2}{|c|}{ Locus C7.900 } & \\
\hline \multicolumn{4}{|l|}{$\mathrm{D} 13.1000 / \mathrm{FT}^{\mathrm{x}}$} \\
\hline XAN-159/XAN-159 & 67 & 48 & 19 \\
\hline $\mathrm{PC}-50 / \mathrm{PC}-50$ & 73 & 71 & 2 \\
\hline \multirow[t]{2}{*}{ Difference } & 6 & $23^{* * \omega}$ & \\
\hline & \multicolumn{2}{|c|}{ Locus BC420.900 } & \\
\hline \multicolumn{4}{|l|}{$\mathrm{E} 4.1150 / \mathrm{FT}^{\mathrm{w}}$} \\
\hline XAN-159/XAN-159 & 18 & 56 & $37^{* * *}$ \\
\hline PC-50/PC-50 & 42 & 55 & $12^{* *}$ \\
\hline \multirow[t]{2}{*}{ Difference } & $24^{* * *}$ & 1 & \\
\hline & \multicolumn{2}{|c|}{ Locus BC420.900 } & \\
\hline \multicolumn{4}{|l|}{$\mathrm{E} 4.1150 / \mathrm{LDT}^{\mathrm{v}}$} \\
\hline XAN-159/XAN-159 & 31 & 69 & $38^{* * *}$ \\
\hline $\mathrm{PC}-50 / \mathrm{PC}-50$ & 56 & 78 & $22^{* *}$ \\
\hline Difference & $25^{* * *}$ & 9 & \\
\hline \multicolumn{4}{|c|}{ 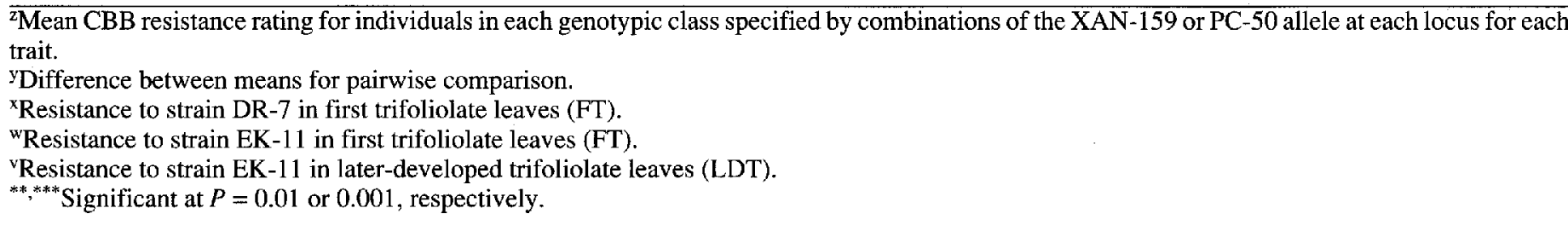 } \\
\hline
\end{tabular}


tively). An additional interaction between marker C7.900 in linkage group 1 and unassigned marker D13.1000 was detected $(P=$ 0.0103 ) for resistance in first trifoliolate leaves to $X c p$ strain DR7. When markers with significant interactions were included in the multiple analysis model, the amount of phenotypic variation of the traits was not improved.

CBB means for each two locus marker genotype were compared (Table 5). The difference between means at the D13.1000 locus was only significant in the presence of the PC-50 allele at the C7.900 locus, while differences at the E4.1150 locus were only significant in the presence of the XAN-159 allele at the BC420.900 locus. For the C7.900 $\times$ D13.1000 interaction, resistance alleles at both loci were contributed by PC-50, while for the $\mathrm{BC} 420.900 \times$ E4.1150 interaction resistance alleles at both loci were contributed by XAN-159. The results suggesting that the difference between the means at the second locus depend on the genotype at the first locus indicate a type of epistasis similar to that reported by Lark et al. (1995) for soybean. If marker-assisted selection for CBB resistance is being considered, such interactions must be taken into account. However, due to the small progeny size in this study, the results reported here must be considered preliminary pending future confirmation.

\section{Literature Cited}

Aggour, A.R., D.P. Coyne, and A.K. Vidaver. 1989. Comparison of leaf and pod disease reactions of beans (Phaseolus vulgaris L.) inoculated by different methods with strains of Xanthomonas campestris pv. phaseoli (Smith) dye. Euphytica 43:143-152.

Ariyarathne, H.M. 1994. Inoculation procedures and heritabilities of the reactions to common bacterial blight in different plant parts in common beans. MS thesis, Univ. of Nebraska, Lincoln.

Amaud-Santana, E. 1992. Genetics and breeding for resistance to common blight, web blight, and rust diseases in dry beans (Phaseolus vulgaris L.). PhD diss., Univ. of Nebraska, Lincoln.

Amaud-Santana, E., D.P. Coyne, K.M. Eskridge, and A.K. Vidaver. 1994. Inheritance; low correlations of leaf, pod, and seed reactions to common blight disease in common beans; and implications for selection. J. Amer. Soc. Hort. Sci. 119:116-121.

Bassett, M.J. 1991. A revised linkage map of common bean. HortScience 26:834836.

Coyne, D.P. and M.L. Schuster. 1974. Differential reaction of pods and foliage of beans (Phaseolus vulgaris) to Xanthomonas phaseoli. Plant Dis. Rpt. 58:278-282.

Coyne, D.P. and M.L. Schuster. 1983. Genetics of and breeding for resistance to bacterial pathogens in vegetable crops. HortScience 18:30-36.

Doebley, J., A. Stec, J. Wendel, and M. Edwards. 1990. Genetic and morphological analysis of a maize-teosinte $\mathrm{F}_{2}$ population: Implications for the origin of maize. Proc. Natl. Acad. Sci. USA 87:9888-9892.

Drijfhout, E. and W.J. Blok. 1987. Inheritance of resistance to Xanthomonas campestris pv phaseoli in tepary bean (Phaseolus acutifolius). Euphytica 36:803808.

Edwards, M.D., C.W. Stuber, and J.F. Wendell. 1987. Molecular marker-facilitated investigations of quantitative trait loci in maize. I. Numbers, genomic distribution, and types of gene action. Genetics 116:113-125.

Edwards, M.D., T. Helentjaris, S. Wright, and C.W. Stuber. 1992. Molecularmarker-facilitated investigations of quantitative trait loci in maize. Theor. Appl. Genet. 83:765-774.

Eskridge, K.M. and D.P. Coyne. 1996. Estimating and testing hypotheses about the number of genes using inbred-backcross data. Heredity 87:410-412.

Freyre, R., S. Warnke, B. Sosinski, and D.S. Douches. 1994. Quantitative trait locus analysis of tuber dormancy in diploid potato (Solanum spp.). Theor. Appl. Genet. 98:474-480.

Jung, G., D.P. Coyne, P.W. Skroch, J. Nienhuis, E. Arnaud-Santana, J. Bokosi, H.M. Ariyarathne, J.R. Steadman, J.S. Beaver, and S.M. Kaeppler. 1996. Molecular markers associated with plant architecture and resistance tor common blight, web blight, and rust in common beans. J. Amer. Soc. Hort. Sci. 121:794-803.
Kosambi, D.D. 1944. The estimation of map distance from recombination values. Ann. Eugen, 12:172 175.

Lander, E.S. and D. Botstein. 1989. Mapping Mendelian factors underlying quantitative traits using RFLP linkage maps. Genetics 121:185-199.

Lander, E.S., P. Green, J. Abrahamson, A. Barlow, M.J. Daly, S.E. Lincoln, and L. Newburg. 1987. MAPMAKER: An interactive computer package for constructing primary genetic linkage maps of experimental and natural populations. Genomics 1:174-181.

Lark, K.G., K. Chase, F. Adler, L.M. Mansur, and J.H. Orf. 1995. Interactions between quantitative trait loci in soybean in which trait variation at one locus is conditional upon a specific allele at another. Proc. Natl. Acad. Sci. USA 92:46564660.

McElroy, J.B. 1985. Breeding dry beans, Phaseolus vulgaris L., for common bacterial blight resistance derived from Phaseolus acutifolius A. Gray. Ph.D. dissertation. Cornell Univ., Ithaca, N.Y.

Mohan, S.T. 1982. Evaluation of Phaseolus coccineus Lam. germplasm for resistance to common bacterial blight of bean. Turrialba 32:489-490.

Nienhuis, J., T. Helentjaris, M. Slocum, B. Ruggero, and A. Schaefer. 1987. Restriction-fragment-length-polymorphism analysis of loci associated with insect resistance in tomato. Crop Sci. 27:797-803.

Nodari, R.O., S.M. Tsai, R.L. Gilbertson, and P. Gepts. 1993a. Towards an integrated linkage map of common bean. II. Development of an RFLP-based linkage map. Theor. Appl. Genet. 85:513-520.

Nodari, R.O., S.M. Tasi, P. Guzman, R.L. Gilbertson, and P. Gepts. 1993b. Toward an integrated linkage map of common bean. III. Mapping genetic factors controlling host-bacteria interactions. Genetics 134:341-350.

Paterson, A.H., S. Damon, J.D. Hewitt, D. Zamir, H.D. Rabinowitch, S.E. Lincoln, E.S. Lander, and S.D. Tanksley. 1991. Mendelian factors underlying quantitative traits in tomato: Comparison across species, generations, and environments. Genetics 127:181-197.

Prakken, R. 1970. Inheritance of colour in Phaseolus vulgaris L. II. A critical review. Mededelingen Landbouwhogeschool Wageningen 70-23:1-38.

Prakken, R. 1972. Inheritance of colours in Phaseolus vulgaris L. III. On genes for red seedcoat colour and a general synthesis. Mededelingen Landbouwhogeschool Wageningen 72-29:1-81.

Saettler, A.W. 1989. Common bacterial blight, p. 261-283. In: H.F. Schwartz and M.A. Pastor-Corrales (eds.). Bean production problems in the tropics. Centro International de Agricultura Tropical (CIAT), Cali, Columbia.

Sanders, J.H. and H.F. Schwartz. 1980. Bean production problems and pest constraints in Latin America, p. 1-14. In: H.F. Schwartz and G.E. Galvez (eds.). Bean production problems. Centro International de Agricultura Tropical (CIAT), Cali, Columbia.

Schuster, M.L., D.P. Coyne, T. Behre, and H. Leyna. 1983. Sources of Phaseolus species resistance and leaf and pod differential reactions to common blight. HortScience 18:901-903.

Shapiro, S.S. and M.B. Wilk. 1965. An analysis of variance for normality (complete samples). Biometrika 52:591-611.

Skroch, P.W. and J. Nienhuis. 1995. Qualitative and quantitative characterization of RAPD variation among snap bean (Phaseolus vulgaris) genotypes. Theor. Appl. Genet. 91:1078-1085.

Thomas, C.V. and J.G. Waines. 1984. Fertile backcross and allotetraploid plants from crosses between tepary beans and common beans. Heredity 75:93-98.

Valladares-Sanchez, N.E., D.P. Coyne, and M.L. Schuster. 1979. Differential reaction of leaves and pods of Phaseolus germplasm to strains of Xanthomonas phaseoli and transgressive segregation for tolerance from crosses of susceptible germplasm. J. Amer. Soc. Hort. Sci. 104:648-654.

Vallejos, C.E., N.S. Sakiyama, and C.D. Chase. 1992. A molecular marker-based linkage map of Phaseolus vulgaris L. Genetics 131:733-740.

Webster, D.M., S.R. Temple, and F.H. Schwartz. 1983. Selection for resistance to Xanthomonas phaseoli in dry beans. Crop Sci. 20:519-522.

Weller, D.M. and A.W. Saettler. 1980. Evaluation of seedborne Xanthomonas phaseoli and $X$. phaseoli var. fuscans as primary inocula in bean blights. Phytopathology 70:148-152.

Williams J.G.K., A.R. Kubelik, K.J. Livak , J.A. Rafalski, and S.V. Tingey. 1990. DNA polymorphisms amplified by arbitrary primers are useful as genetic markers. Nucleic Acids Res. 18:6531-6535

Yoshii, K., G.E. Galvez, and G. Alvarez. 1978. Screening bean germplasm for tolerance to common blight caused by Xanthomonas phaseoli and the importance of pathogenic variation to varietal improvement. Plant Dis. Rpt. 62:343-347. 